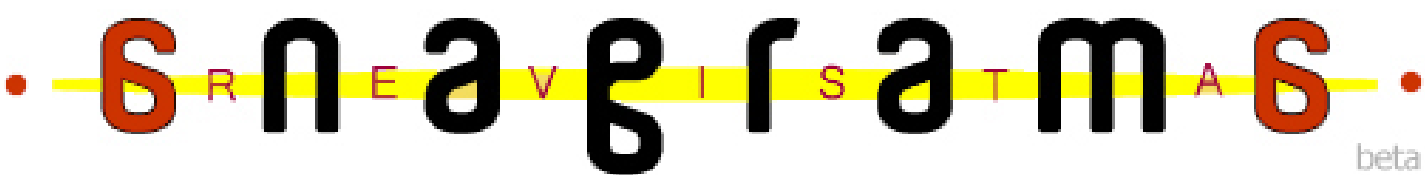

\section{A Publicidade contemporânea e as Teorias de Comunicação de massa}

\section{Diogo Rópora Kawano}

\section{Eneus Trindade ${ }^{2}$}

\section{Resumo}

A partir de leituras de obras clássicas sobre teorias da comunicação, dadas em Wolf(2005) e em Mattelart e Mattelart(2000), busca-se neste trabalho, apontar as principais reflexões teóricas da comunicação que contribuíram, e ainda contribuem, para a compreensão dos processos de comunicação da publicidade e propaganda, de modo a observar tanto as linhas teóricas mais utilizadas na esfera da publicidade, como também abrindo a reflexão para outras teorias e hipóteses menos trabalhadas nos estudos midiáticos da Propaganda.

Palauras-chave: Teorias da Comunicação, Propaganda, Comportamento do consumidor, Mass Communication Research, Linguagem

\section{Introdução}

Diante do final do primeiro decênio do século XXI, a sociedade se vê cada vez mais em um cenário cujo espaço acarreta em constante plasticidade, ora apresentando-se como algo grandioso, ora sublimando-se no imaterial ou virtual. Nesse contexto, a comunicação emerge com um dos principais elementos constitutivos dos processos conjunturais contemporâneos .

Todavia, as mudanças advindas das duas últimas décadas reconfiguraram a dinâmica social, aspecto no qual estão embutidas as relações de consumo. Nesse sentido, faz-se oportuna uma reflexão que procure apontar os principais modelos e linhas acerca das teorias da comunicação que subsidiam os estudos da publicidade e propaganda, a fim de que haja uma melhor compreensão desta relação na atual sociedade globalizada.

\section{A Escola de Chicago}

\footnotetext{
${ }^{1}$ Graduando em Comunicação Social | Publicidade e Propaganda - ECA/USP. Bolsista do Programa Ensinar com Pesquisa da Pró-Reitoria de Graduação da USP.

2 Orientador, Professor Adjunto do Departamento de Relações Públicas, Propaganda e Turismo- ECA/USP.
} 
Tal como era sua caracterização mais evidente no início do século XX, os Estados Unidos construíam seus estudos científicos, fossem eles de caráter natural ou humano, alicerçados em bases empíricas, cuja metodologia visava sempre a uma compreensão por parte dos estudiosos de tal forma que os estudos realizados pudessem vir a ser implementados de modo prático na sociedade, tendo, sobretudo, a política como principal esfera de interesses. Todavia, antes que este último processo pudesse exercer considerável expressão, a Escola de Chicago, menos estratégica do que sociológica, firmou importantes considerações a respeito da dinâmica social e dos estudos empíricos, tão importantes para a época e para os dias atuais.

Tendo como principal representante o repórter Robert Park, os estudos da Escola de Chicago estabeleceram a cidade como ponto-chave de observação, onde os seus "signos de desorganização, de marginalidade, de acumulação e de assimilação...” fariam da cidade um verdadeiro "laboratório social” (MATTELART, 2000, p.30).

Por conseqüência, Parker se utilizou de vários temos da biologia para fundamentar suas observações da cidade. O principal deles, o conceito de "ecologia social", busca exprimir dois diferentes níveis atuantes em uma comunidade, caracterizada pelas relações dos organismos com seu meio.(Mattelart, 2000, p. 32). Desse modo, existiria na comunidade uma contínua relação de busca pelo equilíbrio, estabelecida entre o nível "biótico" e o social/cultural: enquanto naquele se manifestariam os conflitos e competições advindas da natural existência da população em seu território; este último seria regido pela comunicação e pelo consenso, de modo a obter de tais relações uma maior harmonia, possibilitando maiores assimilações e trocas de experiência entre os indivíduos.

Além disso, é desse cenário que emerge uma das principais preocupações que vieram a orientar os fundamentos de marketing e de publicidade. Trata-se de considerar a relação ambivalente entre os processos nos quais se manifestam a individualidade e o nivelamento/homogeneização" do individuo à sociedade. (MATTELART, 2000, p.32). Esta concepção, embora tenha sido tratada pela Escola de Chicago de modo menos abrangente, restringindo-se à metodologia etnográfica (monografias de bairro, observação participante e análise das histórias de vida), é importante ingrediente para compreensão das posturas que o indivíduo prefere embasar seu comportamento, ora optando por assemelharse a uma maioria, ora preferindo experiências únicas que constituam o seu self.. "(MATTELART, 2000, p.36) . 
De fato, o que se tem visto na elaboração das estratégias mercadológicas, tanto através da publicidade quanto por meios das outras ferramentas do marketing, é justamente o alinhamento preciso entre o trabalho dos estrategistas/comunicadores e a postura que o individuo prefere seguir em uma determinada circunstância.

Especificamente no Brasil, a publicidade, aqui com sentido de ações mercadológicas, emergiu no início do século XX, em uma conjuntura de crescimento urbano, com o aumento do poder de compra da sociedade.

Durante praticamente essas seis décadas do início Século XX que se seguiram, a comunicação mercadológica procurou focar sua mensagem de modo a provocar uma identificação entre os consumidores de um mesmo produto, ou seja, apresentando forte apelo à questão de moda e a grupos de referência.

Entretanto, o choque do petróleo, em 1973, exigiu uma mudança em direção a uma postura mais independente das relações econômicas e comportamentais. Foi neste período que se viu uma ascensão de apelos ao caráter personalizado do indivíduo na publicidade. Diferentemente dos Estados Unidos, o Brasil, mais afim à tradição social e coletiva, viu de forma mais tardia o crescimento de peças publicitárias com caráter mais individual, cuja constituição única e pessoal se sobrepujasse aos anseios de semelhança a outros indivíduos ou grupos sociais.

Ainda sim, esta tendência parece ter dado um segundo salto nos últimos dez anos, não somente no Brasil, como também em todos os países de um modo geral, fato que mantém o diálogo com as considerações da Escola de Chicago ainda hoje, principalmente se quisermos pensar na recepção da publicidade e nos estudos das práticas culturais de consumo, que são muitos mais estudadas por aspectos da psicologia e dos efeitos da publicidade, como produto de comunicação de massa.

\section{O Mass Communication Research (MCR)}

O evento-chave que simbolizou o nascimento da MCR foi a Primeira Guerra Mundial, sobretudo, a partir dos primeiros estudos de Harold D. Lasswell, acerca da utilização de técnicas comunicacionais no âmbito da propaganda como ferramenta fundamental para o êxito ou fracasso dos países envolvidos. Assim, de posse desse status prático, foi conferida à comunicação um poder soberano, quase inquestionável em relação à eficácia de seus efeitos. Contudo, faz-se necessária primeiramente uma contextualização 
do cenário vivido durante o período no qual predominou a MCR, a fim de que se possa melhor compreender os motivos que alimentaram esta corrente operacional de comunicação.

A principal área de conhecimento que deu suporte aos estudos do MCR foi a psicologia, com seu enfoque calcado no comportamento do indivíduo frente a estímulos externos, corrente de pensamento que já apresentava suas raízes fincadas ao redor do mundo, cuja primeira metade do século $\mathrm{XX}$ foi o período de maior recrudescimento de tais linhas teóricas, a destacar, a psicologia das massas de Le Bom, o behaviorismo do pioneiro John B. Watson e sua filiação, cujas teorias foram desenvolvidas pelo estudioso russo Ivan Pavlov.

Como conseqüência, a conjuntura de estudos propiciada pela Mass Communication Research abriu horizontes para melhor compreender diversos aspectos relativos ao comportamento do consumidor, fato este essencial para o desenvolvimento da publicidade. Destarte, pode-se mencionar, ainda que brevemente, já que este não é o enfoque deste trabalho, mas sim uma decorrência, quatro posturas-base que orientariam o comportamento de consumo: pavloviana, freudiana, marchaliana e vebleniana.

O comportamento no sentido pavloviano decorre dos estudos fisiológicos realizados pelo médico Ivan Pavlov, que apresenta a relação existente entre sinais sonoros e a salivação e secreção estomacal em cachorros expostos com determinada freqüência aos estímulos auditivos e a alimentação.

Diante dessa tendência de proposições, a idéias de que os processos comunicacionais se manifestassem de modo análogo, via estímulo-resposta, era assaz plausível na época, fato que fez emergir a concepção de "agulha hipodérmica", proposta por Lasswel (Wolf, 2005, p. 05) para evidenciar a audiência como sendo apática, simples e imutável receptora das mensagens advindas dos meios de comunicação.

Em vista de uma abordagem relativamente limitada, a incorporação desta esquemática na esfera mercadológica foi feita com cautela, o que não anula sua validade em peças publicitárias que apresentam sempre uma característica fixa, como cor, chamada ou estrutura argumentativa, visando a uma rápida alusão (resposta) à marca por parte do receptor, o que facilita a construção da identidade e valorização de marca, ou brand equity.

Também proveniente da psicologia, considerado, todavia, a existência do inconsciente, Freud faz surgir outra possibilidade de comportamento de consumo, calcado nas três instâncias que se manifestam no indivíduo: o ID, o EGO e o SUPEREGO (GADE, 
1998). A primeira instância (ID) é o ponto central acerca das quais orbitam a atuação das outras duas, ou seja, é no ID que sobressaem os impulsos primitivos, não somente necessários ao homem, mas também responsáveis por despertar desejos, prazer e interesse, como, por exemplo, os anseios sexuais e de alimentação. Para refrear os impulsos, atuariam o EGO, moderador, e o SUPEREGO, instância mais intensa de regulação social.

Sob esta perspectiva, a publicidade se utiliza com freqüência de anúncios cujo apelo remetem ao ID, através de desejos (intrínsecos ao consumidor), convidando os indivíduos a se libertarem dos "grilhões" sociais e do cotidiano. Por conseguinte, campanhas de agências de turismo que apresentam lugares paradisíacos ou anúncios que contém apelo sexual são assaz ilustrativos de tal aplicação.
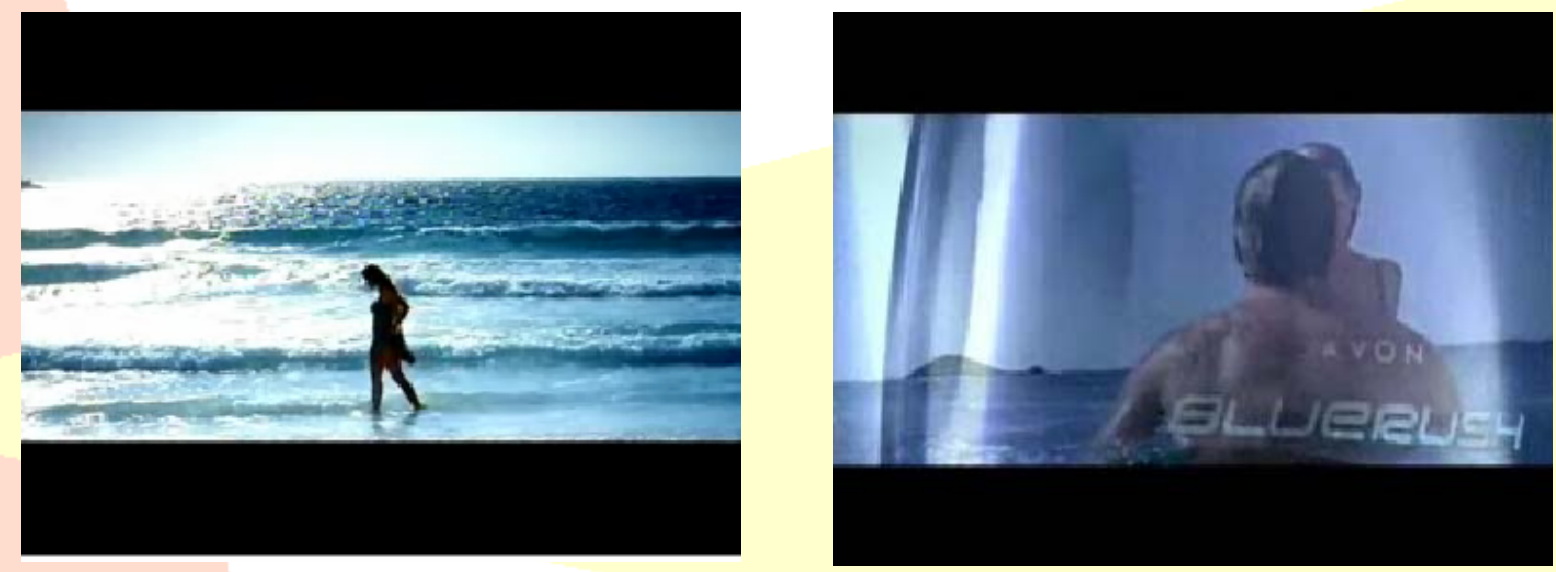

Fonte: http://www.dpz.com.br/novo/portweb/gallery/videos/avon_sensacao_sclaquete.flv

Com relação aos dois comportamentos restantes, tem-se ainda os estudos de Marshall, de abordagem mais racional, cujo enfoque se dá pela avaliação de retorno esperado a um determinado ato. No âmbito mercadológico, esta observação se alinha ao conceito de custo-benefício, também explorado pela publicidade, quando esta tenta evidenciar aspectos técnicos de um produto relacionados com seu preço. E, finalmente, a última postura comportamental de consumo advém do sociólogo Thorstein Veblen que se baseia nas influências sociais externas ao indivíduo, tais como grupos de referência (GADE, 1980, p. 102), familiares ou formadores de opinião. Estas considerações podem ser transpostas com facilidade para a publicidade, uma vez que se vê com freqüência anúncios cuja mensagem é fundamentada no desejo de se equiparar a outrem que possui um determinado status. 
Dando continuidade aos seus estudos, sempre com grande interesse pelas áreas de política, opinião pública e propaganda, o cientista político Lasswell elaborou a uma importante questão que procurar identificar os elementos fundamentais responsáveis pelo processo de comunicação: quem diz o quê? Para quem? Por qual canal e com que efeito? Essas perguntas foram fundamentais para se aprofundar os aspectos referentes a cada um dos elementos. Assim, resultariam, respectivamente, desta premissa as análises de controle, de conteúdo, de audiência, de suporte e dos efeitos(Mattelart, 2000, p.40). Nota-se que, naturalmente, os estudos se direcionaram para a análise conjunta de conteúdo e dos efeitos, áreas de grande aplicabilidade e que rapidamente suscitaram interesses de ordem política (eleições e opinião pública), militar, empresarial e mercadológica.

Tais considerações foram importadas quase que de forma direta aos estudos da publicidade, a fim de que se obtivesse maior êxito junto aos consumidores em adquirir os produtos em função de uma publicidade mais bem elaborada. Dentre as principais decorrências desta tendência, cujo ápice, deu-se conjuntamente com o período do milagre econômico no país, destacam-se os estudos realizados por Farina (1982) sobre a influência e o impacto das cores na percepção do produto por parte dos clientes, a chamada psicodinâmica da comunicação.

Nota-se, também, uma semelhança desses esforços em relação à perspectiva do Mass Communication Reserach, no sentido de que esses estudos eram tidos como os fatores preponderantes, senão únicos, que condicionavam o êxito ou fracasso da comunicação, desconsiderando ainda dinâmicas mais complexas, tais como questões de cunho cultural e dos efeitos de linguagem das comunicações, nas quais estão inseridos não somente os consumidores, mas antes de tudo, os cidadãos-receptores, e essas abordagens serão priorizadas respectivamente pela Escola de Frankfurt e pelos estudos discursivos da publicidade.

Deve-se observar, ainda, que não se pode desconsiderar os estudos feitos acerca da função cromática no processo comunicacional; ao contrário, constituem eles em importante papel na concepção visual de uma peça publicitária, conjuntamente com uma série de outros fatores (organização dos elementos, fontes,etc), fato que os tornam úteis e funcionais até os dias atuais, mesmo diante das mudanças sócio-culturais ocorridas das últimas décadas. 


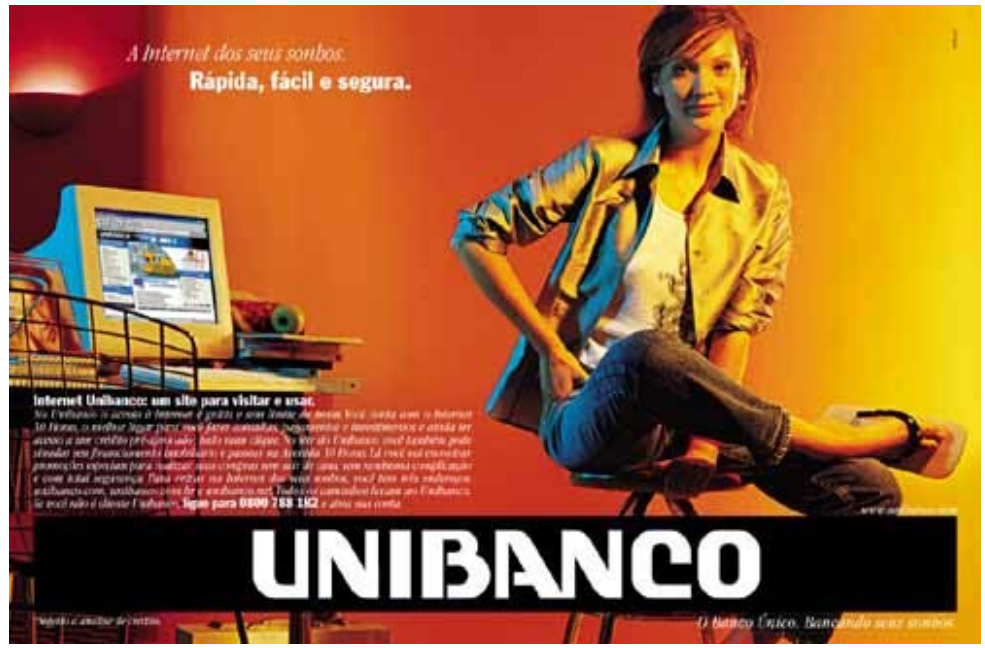

Fundo alaranjado, cor que propõe ambiente convidativo e amigável, ao mesmo tempo que mantém a seriedade. Fonte: http://www.wbrasil.com.br/

Outro estudioso do MCR que trouxe grandes contribuições não somente para a publicidade, como também para a sociologia e para a propaganda política, foi o sociólogo Paul Lazarsfeld. Em colaboração constante de Robert Merton, outro grande sociólogo, Lazrsfeld representou a transição ente o modelo mais restrito desenvolvido por Lasswell e uma abordagem mais multifatorial dos processos de comunicação, adotando de vez, a postura administrativa dos meios de comunicação, de modo a se "preocupar em aperfeiçoar instrumentos de avaliação úteis, operatórios, para os controladores de mídia" (Mattelart, 2000, p.45).

Dentre suas principais contribuições para a área de publicidade e propaganda, temse o modelo que media a aprovação da audiência em relação a um determinado conteúdo. Este aparelho consistia em um painel através do qual cada indivíduo da audiência registrava sua aprovação ou aversão ao conteúdo da mensagem. Desse modo, apertar o botão verde significava aprovação; vermelho aversão. O intervalo de tempo no qual não se apertava qualquer botão era considerado como conteúdo indiferente. Por fim, para registro das reações, era ligada ao painel uma agulha que oscilava ente altos e baixos sobre um cilindro de papel, construindo, assim, um mapeamento da qualidade da mensagem.

Embora na época este aparelho, denominado "Lazarsfeld-Stanton", tenha sido utilizado em larga escala para avaliar programas de rádio e cinema, atualmente, a idéia deste mecanismo é também explorada por profissionais de marketing político, com relação 
a episódios televisivos de propagandas eleitorais, o que não anula a utilização deste método na publicidade, também televisiva, embora tal sistemática seja empregada em menor grau.

Além disso, faz-se necessário ainda apresentar outra grande constatação de Lazarsfeld a respeito do processo comunicacional.

Durante seus diversos estudos acerca das etapas intermediárias à emissão e recepção das mensagens por parte dos indivíduos, Lazarsfeld notou a ocorrência do processo de comunicação em dois níveis, a chamada teoria do Two-Step-Flow (Mattelart, 2000, p.48). Nesta, Lazarsfeld, em parceria com Elihu Katz, atenta para a existência de um degrau entre o pólo emissor e receptor. Este degrau seria constituído por "grupos primários" (Mattelart, 2000, p.48), ou seja, pessoas que estariam mais expostas à informação, em especial a mídia, de modo que elas se tornassem "líderes de opinião", influenciando, assim, a decisão de outras pessoas com que elas tenham contato.
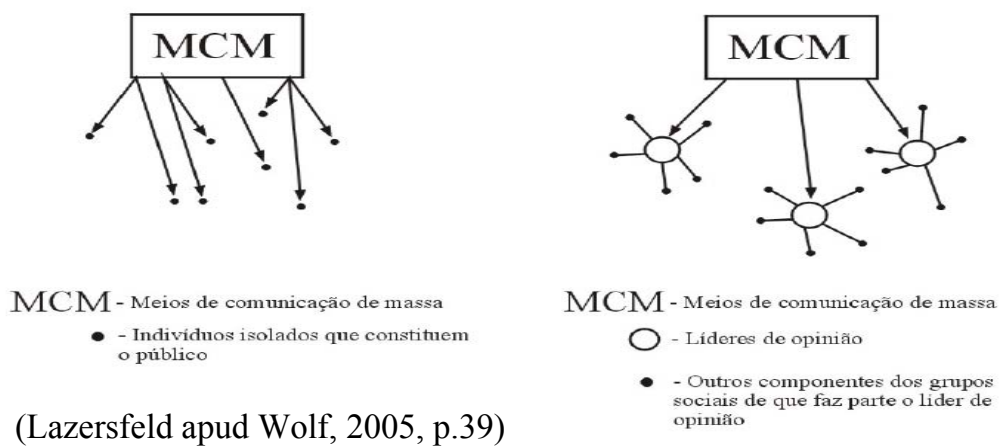

Com este conceito muitas estratégias da publicidade e, sobretudo, do marketing. Fortaleceram a idéia da existência de um líder de opinião, o que permitiu que se começasse a elaborar mensagens dirigidas a grupos formadores de opinião que passariam a se tornar importantes aliado no processo de influência de decisão de compra, fato que não somente reduziu custos desnecessários em comunicação, como também a maximizou a eficácia do processo comunicacional.

\section{A Teoria Crítica}

De forma contemporânea, embora do outro lado do Atlântico, o modelo de estudos adotado pela Escola de Frankfurt, sobretudo, por meio da Teoria Crítica, seguiu uma linha inversa à linha adotada pelos estudos administrativos dos Estados Unidos. Assim, se em uma buscavam-se técnicas mais eficientes de formulação de conteúdo publicitário, os estudiosos da Teoria Crítica vão propor uma avaliação que não somente se contenha em 
avaliar os processos decorrentes da homogeneização da sociedade, mas também, e principalmente, fazer observações críticas sobre os princípios sociais que regeriam tais relações de submissão, como afirma Mattelart:

Escola de pensamento crítico irá se interrogar sobre as conseqüências desses novos meios de produção e transmissão cultural, recusando-se a tomar como evidente a idéia de que, dessas inovações técnicas, a democracia sai-se necessariamente fortalecida. (Mattelart, 2000, p. 73).

Comprometidos com esta questão, os estudiosos da Escola de Frankfurt contribuíram de maneira essencial para o âmbito da publicidade, de forma a possibilitar uma outra perspectiva dela, mais crítica do que encantadora.

$\mathrm{O}$ aspecto fundamental sobre os quais giram as principais elucidações advindas da Escola de Frankfurt é a expressão “indústria cultural”, utilizada por dois grandes ícones desta linha de pensamento: Horkheimer e Theodor Adorno.

Ao contrário do que propunha a expressão "cultura de massa", a Indústria Cultural foi utilizada justamente para substituir o conceito de Comunicação de massa, a fim de se evidenciar um processo um processo que não era gerado espontaneamente por parte da massa, mas sim a ela imposta e de modo padronizado.

Por conseguinte, a sociedade estaria, segundo Adorno e Horkheimer, submetida a um sistema organizado, no qual a cultura, vista como mercadoria, seria comercializada para a sociedade, resultando deste processo um declínio agudo da qualidade desses itens culturais(Wolf, 2005, p.76).

É justamente neste aspecto que a publicidade apresenta-se como um liame entre esse sistema e a sociedade. Sob esta perspectiva, nota-se um duplo papel da publicidade: um enquanto meio pelo qual o sistema produtivo capitalista catalisa seus interesses, e outro enquanto pólo criador e emissor de mensagens cujo conteúdo dão maior coesão às práticas sociais.

Nesse sentido, a publicidade corrobora muitas vezes para os apontamentos da Escola De Frankfurt, como se vê nas figuras abaixo, pertencentes a um filme publicitário do setor de cervejas. 

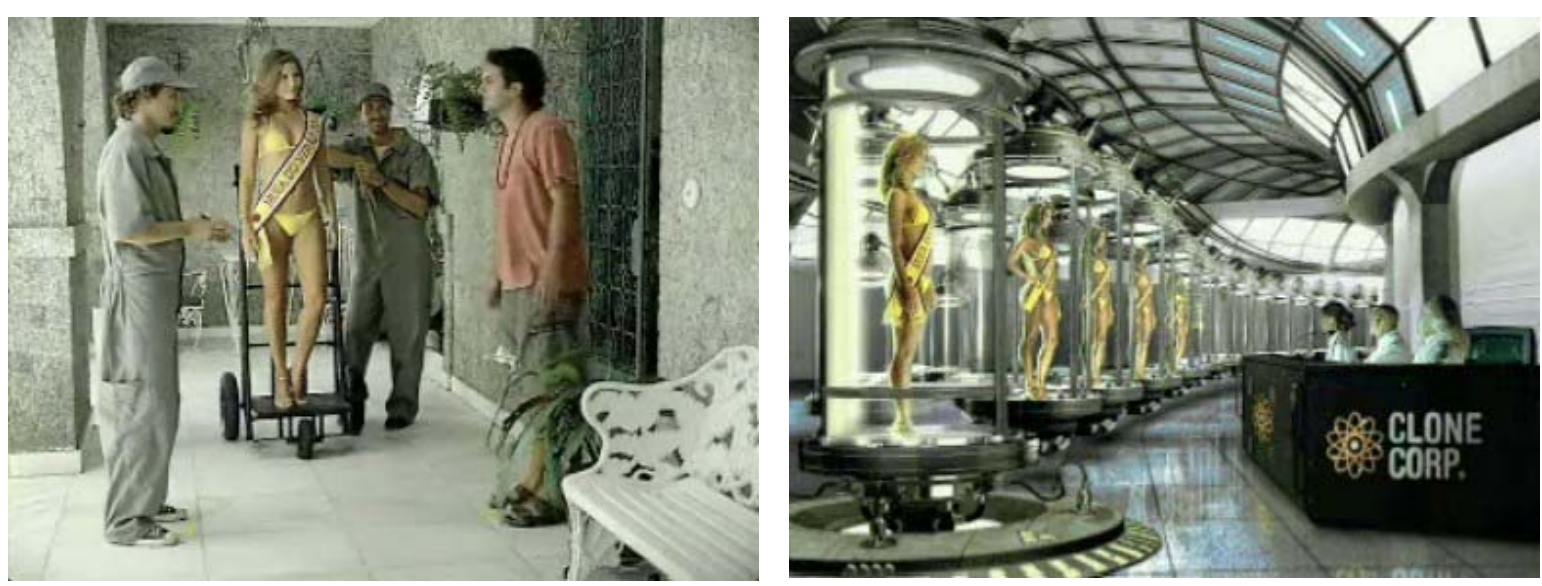

Fonte: http://www.fnazca.com.br/news/news.php?pag=13\&id_news=222\#

Mais importante do que o processo de padronização dos produtos, nota-se acima que o próprio ser humano é representado como mercadoria, fato que além de consolidar a perspectiva crítica, dá mais um passo em colaboração com a sistemática capitalista de consumo.

\section{O Agenda Setting}

Em meio a um cenário cuja preocupação ruma cada vez mais para tentativas de análise que considerem e correlacionem os mais diversos fatores que atuam na constituição pessoal e social do indivíduo, as chamadas hipóteses contemporâneas da comunicação são, também, fontes das quais emanam contribuições para esfera da publicidade e propaganda, sendo provavelmente o Agenda Setting a principal delas.

Elaborada pelos professores norte-americanos Maxwell McCombs e Donald Shaw, o Agenda Setting ou hipótese do agendamento tenta apontar semelhanças notadas entre o conteúdo veiculado pelos meios de comunicação de massa e os temas sobre os quais a sociedade discute em um determinado momento. Assim, assuntos abordados pela mídia tenderiam a ser absorvidos futuramente como parte integrante das preocupações da sociedade, provocando, deste modo, o seu agendamento, como explana Shaw.

\footnotetext{
"As pessoas tendem a incluir ou excluir dos próprios conhecimentos o que a mídia inclui ou exclui do próprio conteúdo. Além disso, o público tende a conferir ao que ele inclui uma importância que reflete de perto a ênfase atribuída pelos meios de comunicação de massa aos acontecimentos, aos problemas, às pessoas." (Shaw apud Wolf, 2005, p. 143)
} 
No entanto, é importante ressaltar um aspecto de absoluta importância referente aos estudos acerca do agendamento. Apesar de haver pesquisas que confirmem a sincronia dos assuntos entre os meios de comunicação e a sociedade, os veículos de comunicação não são capazes de influenciar decisivamente na opinião dos receptores sobre determinado assunto, restringindo, portanto, o poder da mídia em somente "impor" o que se discutir, mas nunca de como o fazer.

Para que se tenha uma melhor compreensão de como esta problemática se relaciona à publicidade, são proveitosos os apontamentos da Escola de Frankfurt, já que esta põe os indivíduos em constante diálogo com os diversos elementos que o cercam, não se restringindo, portanto, seu comportamento a um único fator. Destarte, considerando a publicidade como mais um desses fatores que incidem no indivíduo, e que ela um importante agente nos meios de comunicação em conjunto com as notícias veiculadas pela imprensa sobre um determinado tema, tem-se como resultado a consonância entre os veículos de comunicação, parâmetro este apontado por Wolf (2005, p.168) como fundamental para maior êxito do efeito de agendamento.

Recentemente, pôde-se observar um acontecimento que permite ilustrar a relação de consonância entre a publicidade, a imprensa e a sociedade como um todo. Trata-se da visita da maior autoridade católica ao Brasil, o Papa Bento XVI. Tal acontecimento não somente foi abordado intensamente pelos meios de comunicação, em especial a imprensa, como também foi incorporado à agenda temática da sociedade, com um suporte advindo também da publicidade. O agendamento faz a conexão com a teoria dos usos e gratificações, também afiliada às vertentes psicológicas da mass communication research, buscando identificar atributos que criem uma pré-disposição favorável aos bens anunciados como no anúncio a seguir. 


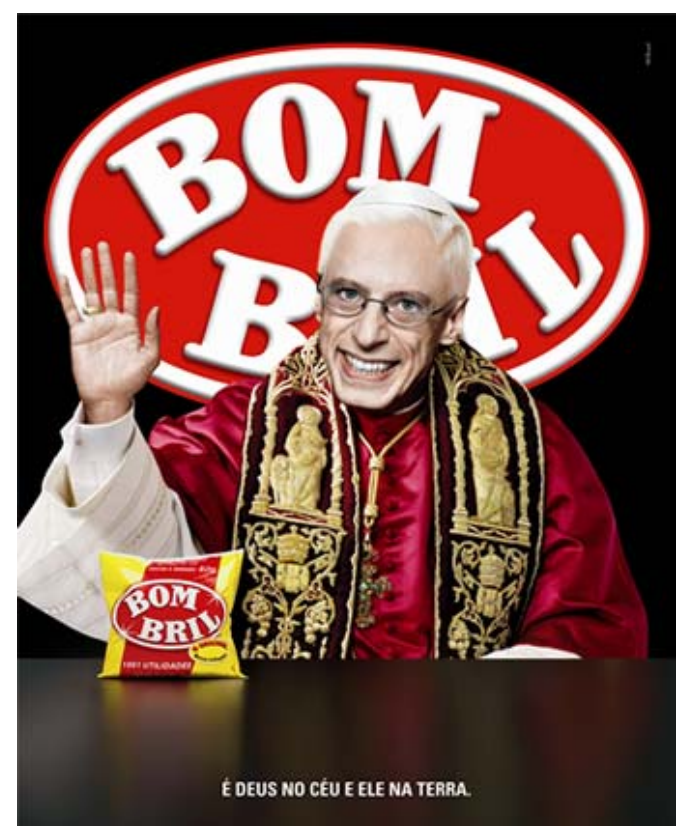

Fonte: http://www.wbrasil.com.br/

\section{Os estudos da linguagem na publicidade}

A linguagem publicitária é outra dimensão fundamental da teoria da comunicação, mas esta é vista por muitos como um meio de abordagem dos públicos, quando na realidade ela se trata de uma referência paradigmática que estuda a representação dos discursos, não apenas da publicidade, mas de toda e qualquer produção discursiva das mídias.

Nessa referência, deparamo-nos com o aspecto possibilitador dos processos comunicacionais, que se constitui pelo fenômeno da linguagem. Toda e qualquer forma de representação, do pensamento e dos processos interação social acontecem na mediação da linguagem como discutem Schaff (1974) e Bakhtin (1995).

Estes dois autores, em suas discussões específicas, formulam reflexões que nos fazem identificar a linguagem e o pensamento como elementos indissociáveis (Schaff,1974) e que se manifestam na dinâmica social, interação social dos indivíduos pela e na linguagem, que a partir de seus signos e em uma dada ambiência discursiva, conseguem estabelecer valores, os significados e os sentidos atribuídos às relações sociais, na medida em que os signos da linguagem refletem e refratam a realidade, conforme o pensamento de Bakhtin (1995,p.31). 
Portanto, os mesmos signos que dão a existência da linguagem são representações sociais que trazem consigo seus conflitos e contradições socioculturais, próprios da condição de existência humana, trazendo também uma lógica de representação que cria estruturas estruturantes, que podem enquadrar neste rol as línguas e os sistemas de linguagem midiáticos. A mídia, como produtora de mensagens é, na dimensão institucional social, um sujeito produtor e decodificador de discursos/mensagens, cujas linguagens se caracterizam como estruturas estruturantes, capazes de veicular ideologias (valores, significações e sentidos), em mensagens, estruturas estruturadas, que em si trazem representações que veiculam sentidos para e sobre os mundos em que circulam.

Dessa maneira, recorremos aos postulados de Foucault (1995), para justificar que as representações, em suas manifestações de linguagem, ambiências discursivas, indicam uma dimensão epistêmica, ou seja, uma forma de conhecer o mundo, o que implica considerar os estudos sobre os efeitos e sentidos das linguagens midiáticas como locais legítimos para a análise e reflexão das representações sociocuturais, passíveis de investimentos teóricos na área da linguagem (lingüística e semióticas) que, ao longo do Século XX, trouxeram grandes contribuições para os estudos da comunicação.

A exemplo desse tipo de contribuição indicamos a leitura do artigo de SANTARELLI e SOUZA (2006), onde as autoras resgatam os principais modelos de leitura das mensagens publicitárias nas referências teóricas da semiologia à semiótica francesa e seus desdobramentos nos estudos contemporâneos da linguagem publicitária.

Nesses estudos as mensagens/discursos, como objetos autônomos, ganham vida durante a sua veiculação nos meios, manifestando intencionalidades próprias, que trazem marcas do pólo da emissão e do pólo da recepção, ainda que este último pólo se apresente na perspectiva de leitura idealizada ou programada pelas intencionalidades do primeiro. A mensagem publicitária, como qualquer discurso, é espelho de seu tempo e espaço, modulando o ser dos indivíduos que por ela são estimulados, em um processo de duas vias, o que coloca a linguagem publicitária como co-fabricadora das realidades.

Nos trabalhos sobre linguagem publicitária cabem os estudos estéticos, estilísticos, de retórica, de argumentação sobre os processos de significação e produção de sentido das mensagens de propaganda. Isso engloba também os estudos dos mecanismos formais da enunciação discursiva (sujeito, espaço e tempo), em suas várias possibilidades de manifestação dos discursos da publicidade e da propaganda, considerando a sua pluralidade sígnica materializada em expressões verbais e não-verbais. Os estudos e 
críticas sobre a produção de sentido dos discursos da propaganda são muitos freqüentes e têm aberto caminhos profícuos para o diálogo com as demais dimensões da comunicação publicitária.

\section{Considerações finais}

Exposto o conteúdo da reflexão, nota-se que as considerações construídas ao longo do século XX a respeito dos processos comunicacionais, sejam eles provenientes da América ou da Europa, ainda dialogam com o âmbito da publicidade e propaganda, mesmo com o decorrer de várias décadas que resultaram em grandes mudanças no comportamento da sociedade e, naturalmente, do consumidor. Viu-se também que a relação existente entre as teorias não se dá de maneira eqüitativa, mas sim em maior ou menor proximidade com os atuais padrões da dinâmica social, fato que parece evidenciar uma maior compatibilidade com as teorias cujos apontamentos procuram compreender o indivíduo no espaço de modo complexo, onde inúmeros fatores são responsáveis por modificá-lo, tanto em curto como em médio prazo.

Assim, são proveitosos os estudos da Escola de Frankfurt, bem como os apontamentos da fase final do Mass Communication Research, bem como os estudos da linguagem publicitária. Finalmente, notam-se ainda presentes na publicidade tanto abordagens mais pontuais e antigas, frutos das primeiras décadas dos estudos administrativos, tais como comportamento e a psicodinâmica das cores, como também hipóteses mais recentes, a exemplo do processo de agendamento da sociedade proposto pelo Agenda Setting, cuja contribuição também parece emanar da publicidade.

Mas é importante destacar que, pela tradição da pesquisa científica purista, a filiação a uma dessas abordagens, implica na negação das outras, o que dificulta os avanços na pesquisa desta área da comunicação, centrada principalmente na Teoria Crítica, nas teorias da Mass Communication Research e nos estudos da linguagem, pois a complexa compreensão da publicidade e propaganda depende de uma visão interdisciplinar capaz de transitar em várias dessas abordagens, dependendo dos interesses de pesquisa, resgatando inclusive os princípios empiristas da Escola de Chicago e da antropologia aos estudos da propaganda, essencialmente no que diz respeito às relações com a recepção publicitária e as práticas de consumo delas decorrentes. Tudo isso cria um novo e 
complexo repertório teórico para futuras leituras mais inovadoras a serem empreendidas sobre a comunicação midiática publicitária.

\section{Referências Bibliográficas}

BAKHTIN, M. (VOLICHINOV). Marxismo e filosofia da linguagem. São Paulo: Hucitec.1995.

FARINA, Modesto. Psicodinamica das cores em publicidade. São Paulo: Edgard Blucher, 1990.

GADE, Christiane. Psicologia do consumidor. São Paulo: EPU, 1980.

KAZ, E.; LAZARSFELD, P. Personal influence: the Part Played by people in the flow os Mass Communications, Free Press, New Yaork, 1955.

MATTELART, Armand e MATTELART, Michèle,. Histórias das teorias da comunicação.3.ed. São Paulo: Loyola, 2000.

WOLF, Mauro. Teorias das Comunicações de Massa. São Paulo : Martins Fontes, 2005.

SANTARELLI, C. e SOUZA, S. M.R. de. Análise da imagem publicitária: revisão de alguns modelos. XXI Congresso da INTERCOM. Brasília: UNB/INTERCOM. $1^{\circ}$.CDROM

SCHAFF, A. A linguagem e o conhecimento. Coimbra: Almedina.1974.

$<$ http://www.dpz.com.br/novo/portweb/gallery/videos/avon_sensacao_sclaquete.flv> Acesso em: 15 mai. 2007.

<http://www.wbrasil.com.br/>. Acesso em: 15 mai. 2007.

$<$ http://www.fnazca.com.br/news/news.php?pag=13\&id_news=222\#>. Acesso em: 15 mai. 2007. 